\title{
Management of heart failure with His bundle pacing in right bundle branch block: Case report
}

\author{
Manejo de la insuficiencia cardiaca con estimulación hisiana en bloqueo de rama \\ derecha: reporte de caso
}

\author{
Jorge Gómez-Flores ${ }^{1 *}$, Jovana Pérez-Báez ${ }^{1}$, Guillermo Muñoz ${ }^{1}$, Gabriela Bustillos-García ${ }^{1}$, Alan García ${ }^{1}$, \\ Álvaro E. Reyes-Quintero', Rosa M. Ávila-Ocampo², Antonio Arias-Godínez², Manlio Márquez', \\ Luis Colin-Lizalde', Moisés Levinstein-Jacinto ${ }^{1}$, José L. Morales-Velázquez ${ }^{1}$, and Santiago Nava ${ }^{1}$ \\ ${ }^{1}$ Department of Electrophysiology; ${ }^{2}$ Department of Echocardiography. Instituto Nacional de Cardiología "Ignacio Chávez," Mexico City, Mexico
}

\begin{abstract}
Cardiac resynchronization therapy has proven to be an effective therapy in patients with left bundle branch block and heart failure. Male, 47 years old, heart failure with a left ventricle ejection fraction of 17\%, idiopathic heart failure. ECG with sinus rhythm, $1^{\text {st }}$ degree AV block, PR 400 ms, complete right bundle branch block, anterior hemi-fascicle of the left bundle of His, and QRS duration 200 ms. We decided to perform a selective His bundle pacing. In patients with right bundle branch block the biventricular cardiac resynchronization is not indicated due to low treatment response. His bundle pacing allows recruiting the blocked branch and restoring conduction throughout it; therefore, in the absence of necrosis the biventricular synchrony is achieved. We presented a case of his bundle pacing with recruitment of the right bundle branch, which reestablish biventricular synchrony measured by speckle tracking, and with a significant increase of the left ventricle ejection fraction from 17 to $36.6 \%$, with an absolute increase of $19.6 \%$.
\end{abstract}

Key words: Cardiac resynchronization. Right bundle branch block. His bundle pacing. Heart failure. Mexico.

\section{Resumen}

La terapia de resincronización cardiaca mediante estimulación hisiana ha demostrado ser efectiva en pacientes con bloqueo de rama izquierda del haz de His e insuficiencia cardiaca. Paciente masculino, con 47 años de edad, con insuficiencia cardiaca, fracción de expulsión del 17\% y miocardio dilatada idiopática, electrocardiograma en ritmo sinusal, bloqueo auriculoventricular de $1 .^{\text {er }}$ grado, intervalo PR 400 ms, bloqueo completo de rama derecha del haz de His, bloqueo del fascículo anterior de la rama izquierda del haz de His, duración del QRS 200 ms. Se decidió realizar estimulación selectiva del haz de His. La resincronización cardiaca biventricular convencional en pacientes con presencia de bloqueo completo de la rama derecha del haz de His no está indicada debido a la pobre respuesta al tratamiento. La estimulación hisiana permite reclutar la rama bloqueada y reestablecer la conducción a través de ella, de tal forma que, en ausencia de necrosis, se logre sincronía biventricular. En el caso presentado el reclutamiento de la rama derecha mediante estimulación hisiana se reflejó en el restablecimiento de la sincronía biventricular, medida por rastreo de marcas (speckle tracking) e incremento significativo de la fracción de expulsión del ventrículo izquierdo del 17 al 36.6\%, con un incremento absoluto del $19.6 \%$.

Palabras clave: Resincronización. Bloqueo de rama derecha. Estimulación hisiana. Insuficiencia cardiaca. México.

\section{Correspondence:}

*Jorge Gómez-Flores

E-mail: jorge.gomez@ cardiologia.org.mx
Date of reception: $17-12-2019$

Date of acceptance: 05-11-2020

DOI: 10.24875/ACME.M21000177
Available online: 25-05-2021

Arch Cardiol Mex (Eng). 2021;91(1):83-89 www.archivoscardiologia.com license (http://creativecommons.org/licenses/by-nc-nd/4.0/). 


\section{Introduction}

Cardiac resynchronization therapy (CRT) consists of implantation of a biventricular pacing device (which may or may not be accompanied by defibrillation) for patients with heart failure that is intended to improve atrioventricular, interventricular, and intraventricular electrical synchrony, as well as left ventricular systolic volume ${ }^{1}$.

Clinical practice guidelines indicate the use of CRT for patients with heart failure (New York Heart Association [NYHA] class II-IV), left ventricular ejection fraction (LVEF) $<35 \%$, QRS > $150 \mathrm{~ms}$, and left bundle branch block (LBBB) morphology (Class I indication, level of evidence $A)^{2}$. There are no conclusive studies that demonstrate the benefit of biventricular pacing in the presence of right bundle branch block (RBBB) ${ }^{3}$. However, current CRT guidelines indicate as a Class Ila recommendation: for patients with LVEF $\leq 35 \%$, normal sinus rhythm, block pattern other than LBBB, QRS $\geq 150 \mathrm{~ms}$, and NYHA Class III; and Ilb for patients with a block pattern other than LBBB and QRS from 120 to $150 \mathrm{~ms}^{4}$.

Selective stimulation of the His bundle allows the recruitment of native His-Purkinje system in those patients with interventricular conduction disorder (LBBB, RBBB) and supra- and infra-Hisian atrioventricular (AV) block and, therefore, it improves interventricular synchrony and LVEF 5 .

Selective stimulation of the His bundle can be successfully performed simultaneously with left ventricular stimulation with electrode on the coronary sinus (His-optimized CRT or "HOT CRT") ${ }^{6}$. There is the technical possibility of placing the His bundle stimulation electrode on the right ventricular connection port of the CRT generator and thus reducing QRS amplitude and generating adequate resynchronization. At present, the most widely used method is by placing the Select Secure electrode (Medtronic Inc, Minneapolis, USA) connected to the right ventricular port of a conventional pacemaker, either single-chamber in the presence of atrial fibrillation or dual-chamber?

A case of His bundle stimulation as a resynchronization method is presented.

\section{Clinical case}

Forty-seven-year-old man diagnosed with idiopathic cardiomyopathy at dilated phase, NYHA functional Class III heart failure, intraventricular, interventricular, and atrioventricular conduction disorder due to the presence of RBBB, anterior fascicular block (AFB), and $1^{\text {st }}$ degree AV block. Heart failure worsened four months before admission, despite maximum medical therapy, with evolution characterized by the lower limb edema, moderate to slight exertion dyspnea, paroxysmal nocturnal dyspnea and orthopnea (NYHA functional Class IV); dizziness, blurred vision, and syncope in three occasions with full recovery. Consequently, he received hospital care, with transient complete AV block alternating with normal sinus rhythm, RBBB, and basal AFB being then documented. On baseline transthoracic echocardiogram, LVEF of $17 \%$, dilated left atrium and ventricle and global left ventricular hypokinesia were reported. In the study of myocardial perfusion by nuclear medicine performed with technetium 99, severe inferoapical and septobasal ischemia and moderate ischemia in the middle segment of the anterior wall were observed. Coronary angiography demonstrated an absence of coronary lesions.

Baseline electrocardiogram (ECG) (Fig. 1) in normal sinus rhythm with $1^{\text {st }}$ degree AV block with PR interval of $400 \mathrm{~ms}$, heart rate (HR) $66 \mathrm{bpm}$, QRS electric axis $-60^{\circ}$, QRS $200 \mathrm{~ms}$, RBBB, and AFB.

On simple and contrast-enhanced nuclear magnetic resonance imaging, left cavities dilated diameters, severe biventricular systolic dysfunction, LVEF of $19 \%$, right ventricular ejection fraction of $15 \%$, and diffuse areas late enhancement with pattern suggestive of non-active myocarditis were observed.

During hospitalization, he had an episode of sustained monomorphic ventricular tachycardia with no hemodynamic compromise, which was managed with amiodarone. In view of the data consistent with acute heart failure, NYHA functional Class III, QRS of $180 \mathrm{ms,}$ presence of $1^{\text {st }}$ degree AV block and AFV-associated RBBB, carrying out selective stimulation of the His bundle plus implantable defibrillator with CRT (CRT-D) was decided.

\section{Procedure description}

Through femoral venous access, a quadrupole catheter was placed in the area of the His bundle, the potential was recorded in the polygraph and infra-Hisian AV block was confirmed, with an HV interval duration of $147 \mathrm{~ms}$.

After asepsis and antisepsis of the left infraclavicular region, left deltopectoral incision, dissection by planes and subcutaneous marsupialization were performed. 


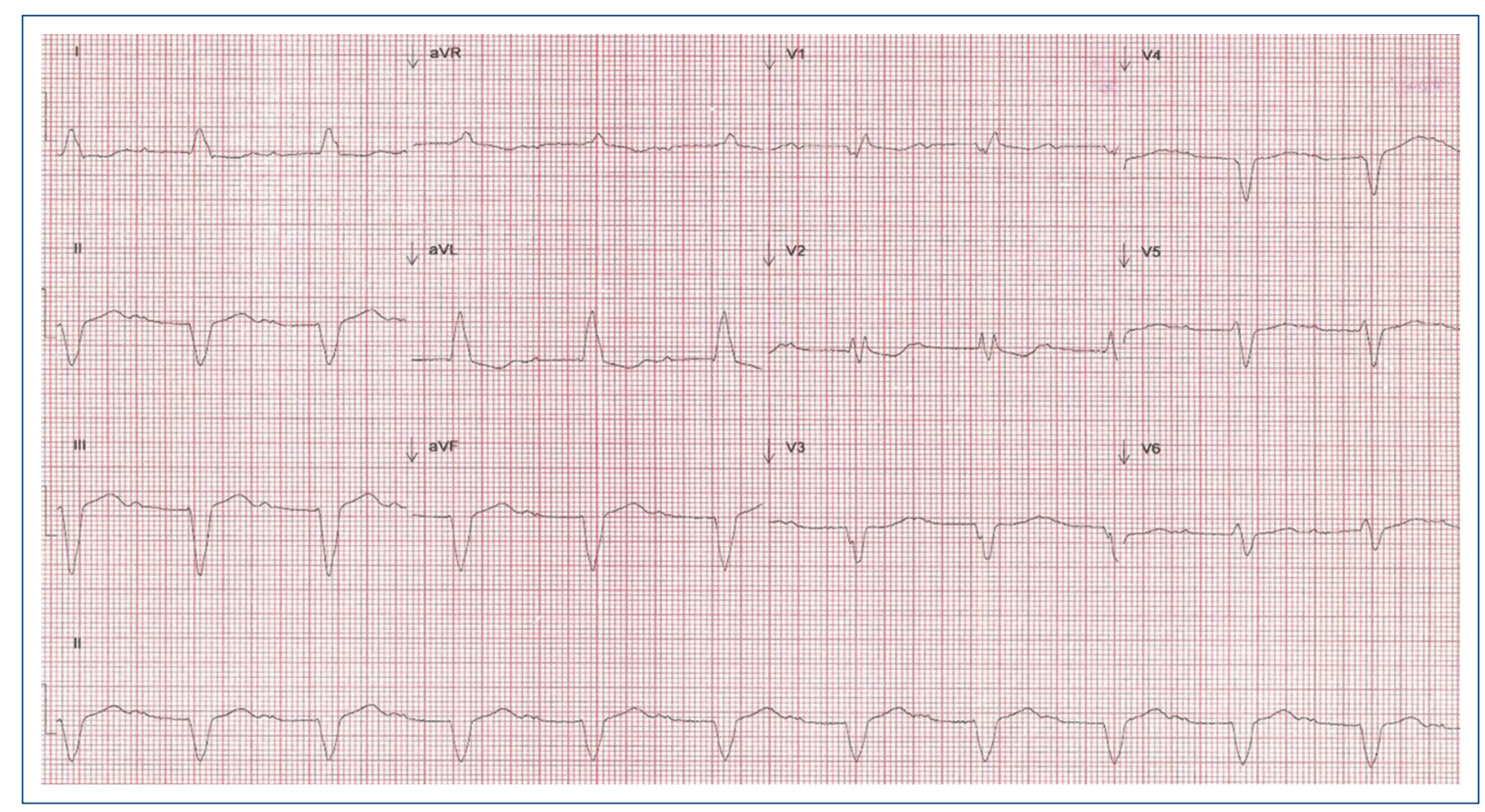

Figure 1. Electrocardiogram before Hisian stimulation. Normal sinus rhythm with $1^{\text {st }}$ degree atrioventricular block with PR interval of $400 \mathrm{~ms}$, heart rate $66 \mathrm{bpm}$, QRS electrical axis of $-60^{\circ}$, QRS $200 \mathrm{~ms}$, right bundle branch block, and anterior fascicle block.

Venous access was obtained by puncture of the left subclavian vein with Seldinger needle, with the metal guidewires to the inferior vena cava being placed. A $6 \mathrm{Fr}$ introducer was placed, through which the C315 HIS preformed sheath (Medtronic Inc, Minneapolis, USA) was advanced, with the Select Secure electrode (Medtronic Inc, Minneapolis, USA) being advanced through it toward the bundle of His; once the site with the best record of the His bundle with a 16-mV R wave was reached, pacing was carried out in unipolar mode at $10 \mathrm{mV}$ with $1 \mathrm{~ms}$ pulse width; on the 12-lead ECG, a decrease in the QRS interval duration to $140 \mathrm{~ms}$ was observed; the output was then progressively decreased to $5 \mathrm{~V}$ with an increase in QRS duration to $152 \mathrm{~ms}$, until Hisian capture was obtained with recruitment of the right branch.

The rest of the procedure was carried out in a conventional manner. Fluoroscopy time was $20 \mathrm{~min}$.

ECG with pacing was obtained: R-R interval $929 \mathrm{~ms}$, QRS duration $160 \mathrm{~ms}$, and QT $525 \mathrm{~ms}$. It was programmed with the following parameters: DDD mode, basic HR $60 \mathrm{bpm}$, maximum HR $130 \mathrm{bpm}$, atrial output $3.5 \mathrm{~V}, 0.4-\mathrm{ms}$ pulse width, output on Hisian pacing site of $5 \mathrm{~V}$, and 1-ms pulse width.

Twenty-four hours after the procedure, an ECG was obtained, which showed a reduction in QRS duration
(Fig. 2). Echocardiographic evaluation was performed before and after CRT using the speckle tracking technique without pacing, where a delay was observed in anterior and posterior walls conduction with regard to the septal wall, which is explained by the AFB (Fig. 3). After pacing, there was significant improvement of interventricular and intraventricular dyssynchrony, and final 3D LVEF quantification with Syngo software in Siemens Accuson S2000 was 36.6\% (Fig. 4).

Eight months after CRT, the patient is asymptomatic, with quality of life and functional class improvements (NYHA I).

\section{Discussion}

CRT has shown an improvement in the survival of patients with heart failure, with improvements in various indicators such as left ventricular remodeling reversal, increased exercise capacity, heart failure-associated hospitalization rate reduction, and a mortality rate decrease $^{8}$. The goal of resynchronization is to achieve coordination of the contraction pattern of the walls opposed to those that show synchrony alteration in the left ventricle ${ }^{9}$.

However, in the presence of RBBB, no benefit has been demonstrated with CRT; in patients with RBBB 


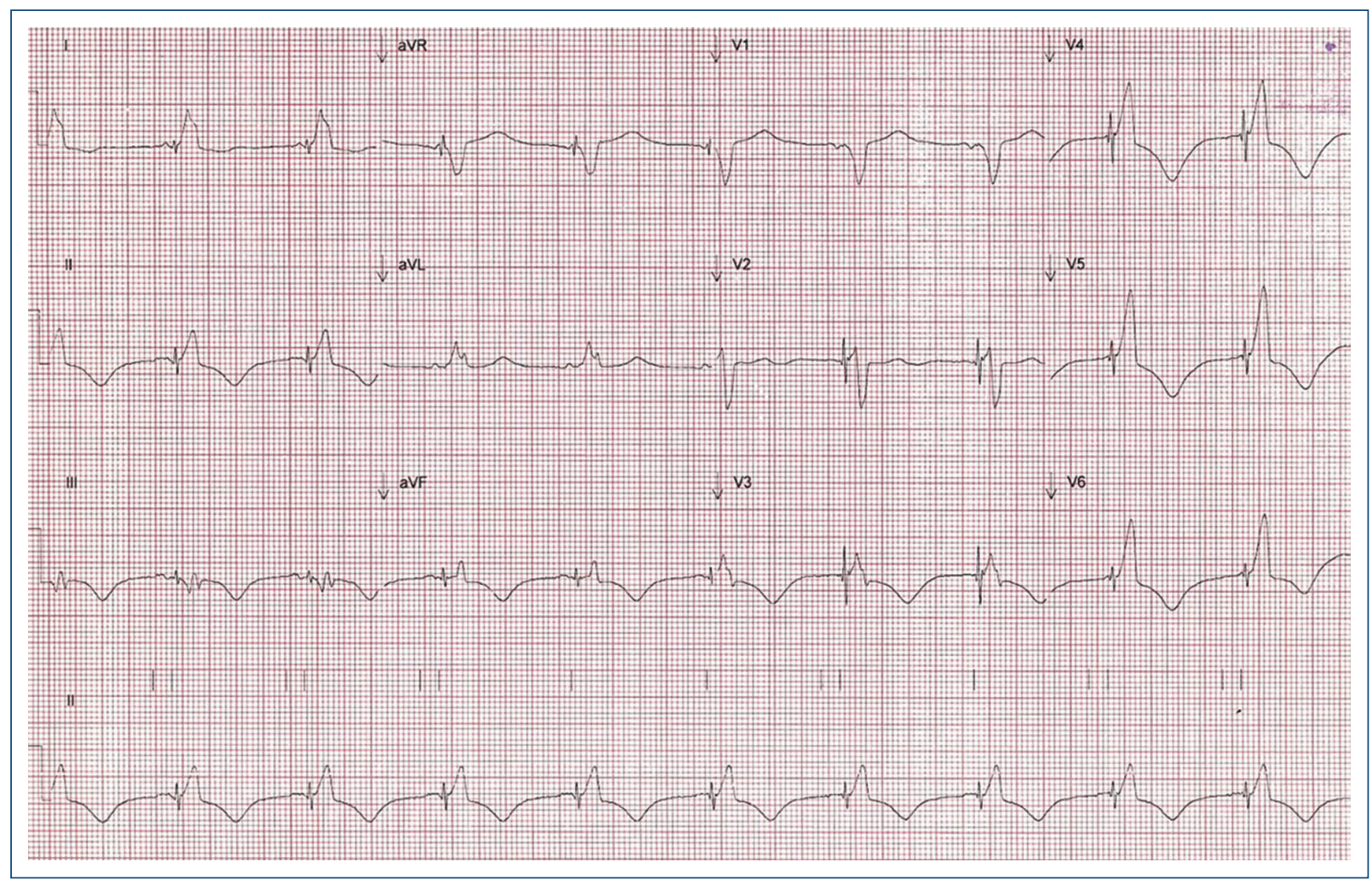

Figure 2. Electrocardiogram after His bundle pacing. R-R interval: $929 \mathrm{~ms}$, QRS duration: $160 \mathrm{~ms}, \mathrm{QT}: 525 \mathrm{~ms}$, left bundle branch block.

and concomitant AFB, Chandra et al. ${ }^{10}$ reported a better response to CRT, defined as an increase in LVEF $>5 \%$ or improvement in NYHA functional class. On the other hand, another group (Varma et al. ${ }^{11}$ ), studied left ventricular inferolateral activation delay by measuring the distance between the start of QRS on ECG and left ventricular intrinsic activation on endocavitary registration, in patients with left ventricular dysfunction and RBBB, in comparison with a group with LBBB; they found a better response to CRT in patients with LBBB.

Hisian pacing has been recently described as a viable alternative to biventricular pacing in patients with indication for cardiac resynchronization ${ }^{12}$.

His bundle pacing can result in correction or recruitment of the right branch with QRS narrowing. Considering that electrical activation in patients with RBBB shows a delay in the right ventricle with minimal or no alteration of the left ventricle, right ventricular activation delay synchronization and left ventricular normal activation is possible by Hisian pacing. It can be achieved by means of two strategies: (1) recruitment of His bundle right branch and normalization of right ventricle activation delay, and (2) in cases where there selective stimulation of the His bundle is not achieved, the fusion between Hisian pacing (with RBBB pattern) and right ventricular pacing corrects the activation delay and is also effective. A favorable effect of Hisian pacing is that it does not generate left ventricular dyssynchrony, since activation occurs by the His-Purkinje system, whereas traditional CRT (biventricular pacing), when applied in patients with preserved left branch activation, results in prolongation of the left ventricular activation time relative to normal sinus rhythm ${ }^{13}$.

Sharma et al. ${ }^{14}$, in a study carried out in 2018 , evaluated the impact of His bundle permanent pacing in a group of patients with RBBB and cardiac resynchronization indication for QRS duration and, after 15 months of follow-up, they demonstrated a significant reduction in QRS duration (158-127 ms), LVEF increase (31-39\%), and functional class improvement.

As previously documented in multiple reports in the literature and, in this case, the Hisian pacing technique was shown to be useful, safe and efficacious in patients with heart failure, RBBB and wide QRS as an 


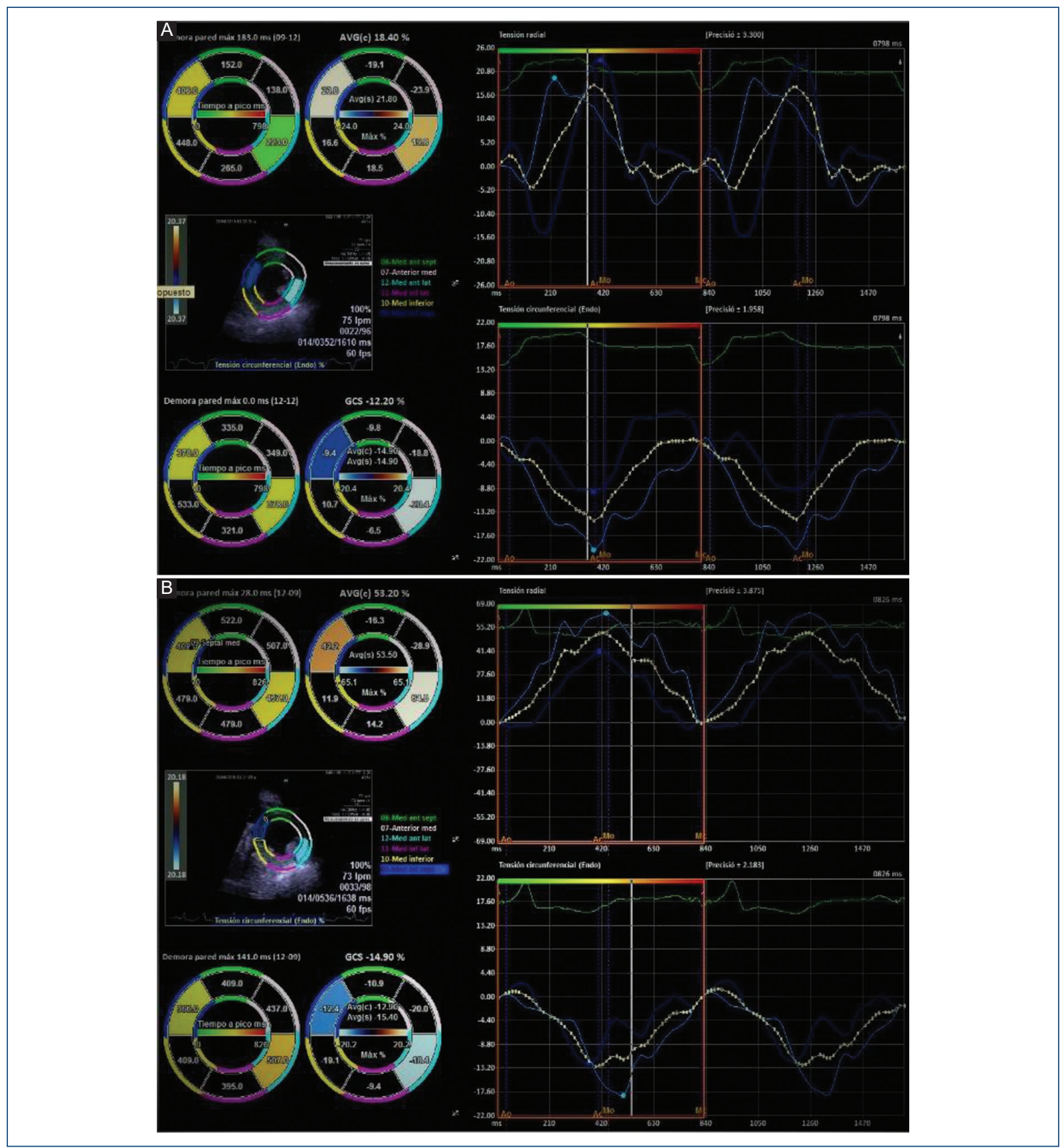

Figure 3. Radial and circumferential strain using speckle tracking technique with analysis by vectors. A: before His bundle pacing, intraventricular asynchrony is shown with a radial strain peak time delay of 183 ms between the anteroseptal and inferior wall, with a strain delay index of $32 \%$. B: after pacing, a reduction in the delay time is shown in the peak radial strain of up to $28 \mathrm{~ms}$, with an improvement of anteroseptal strain delay index as well.

alternative therapy to conventional cardiac resynchronization, with good short-medium term results in appropriately selected patients with QRS duration $>150 \mathrm{~ms}$ on baseline ECG, or in case of being lower, intraventricular dyssynchrony should be evaluated by transthoracic echocardiogram, ideally with radial strain.
In our case, given the improvement we observed in LVEF from 17 to $36.6 \%$, it is possible that this group of patients might no longer be eligible for the defibrillator implant indication as primary prevention; therefore, observing series of multicenter studies where the response can be assessed will be necessary. 


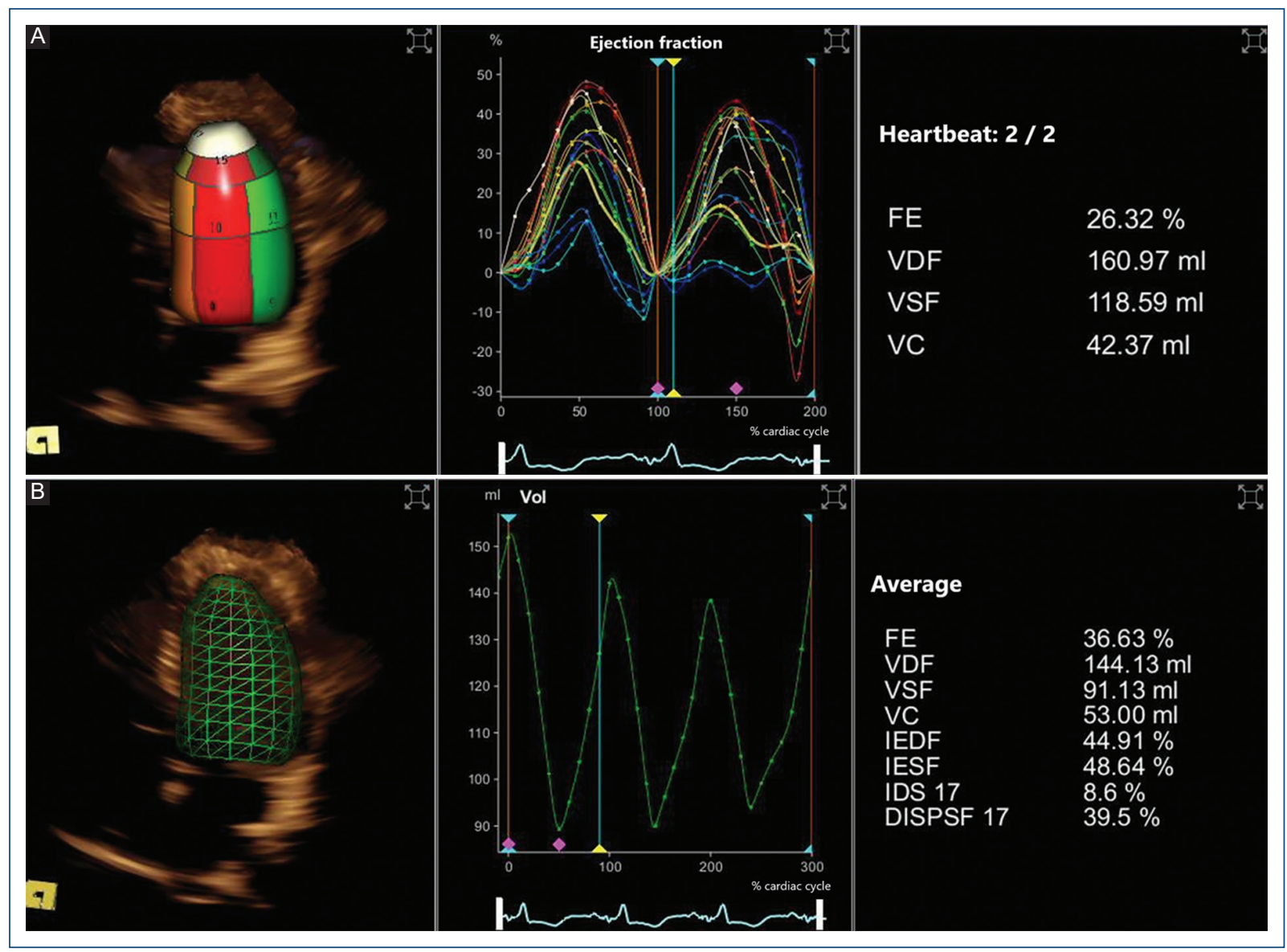

Figure 4. Left ventricular ejection fraction (LVEF) 3D quantification. A: the ejection fraction (EF)/time curve is $26.32 \%$. B: after cardiac resynchronization therapy and His bundle pacing, it is $36.6 \%$, with an improvement of $10.31 \%$ in LVEF being observed. Final diastolic volume (FDV) decreased from $160.97 \mathrm{~mL}(\mathrm{~A})$ to $144.13 \mathrm{~mL}(\mathrm{~B})$. Final systolic volume (FSV) decreased from $118.59 \mathrm{~mL}(A)$ to $91.13 \mathrm{~mL}(B)$. Stroke volume (SV) increased from $42.37 \mathrm{~mL}(A)$ to $53 \mathrm{~mL}(B)$. In $\mathrm{graph}$ $B$, volume/time curve, an improvement of $10.63 \mathrm{~mL}$ was identified in stroke volume with regard to baseline.

\section{Funding}

None.

\section{Conflicts of interest}

The authors declare that they have no conflicts of interest.

\section{Ethical disclosures}

Protection of human and animal subjects. The authors declare that the procedures that were followed adhered to the ethical standards of the responsible committee for experimentation in human subjects and were in agreement with the World Medical Association and the Declaration of Helsinki.
Confidentiality of data. The authors declare that they have followed the protocols of their work center on the publication of patient data.

Right to privacy and informed consent. The authors have obtained informed consent from the patients and/or subjects referred to in the article. This document is in the possession of the corresponding author.

\section{References}

1. Curtis AB, Worley SJ, Adamson PB, Chung E, Niazi I, Sherfesee L, et al. Biventricular pacing for atrioventricular block and systolic dysfunction. $\mathrm{N}$ Engl J Med. 2013;368:1585-93.

2. Brignole M, Auricchio A, Baron-Esquivias G, Bordachar P, Boriani G Breithardt $O A$, et al. 2013 Guidelines on cardiac pacing and cardiac resynchronization therapy. Eur Heart J. 2013;34:2281-29.

3. Tang AS, Wells GA, Talajic M, Arnold MO, Sheldon R, Connolly S, et al: Resynchronization-Desfibrillation for Ambulatory Heart Failure Trial Investigators. Cardiac-resynchronization therapy for mild-to-moderate heart failure. N Engl J Med 2010;363:2385-95. 
4. Epstein AE, DiMarco JP, Ellenbogen KA, Estes NA III, Freedman RA Gettes LS, et al. 2012 ACCF/AHA/HRS focused update incorporated into the ACCF/AHA/HRS 2008 guidelines for device-based therapy of cardiac rhythm abnormalities: a report of the American College of Cardiology Foundation/American Heart Association Task Force on Practice Guidelines; Heart Rhythm Society. J Am Coll Cardiol. 2013:61:e6-e75.

5. Sharma PS, Dandamudi G, Naperkowski A, Oren JW, Storm RH, Ellenbogen KA, et al. Permanent His-bundle pacing is feasible, safe, and superior to right ventricular pacing in routine clinical practice. Heart Rhythm. 2015;12:305-12.

6. Vijayaraman P, Herweg B, Ellenbogen K, Gajek J. His-optimized cardiac resynchronization therapy to maximize electrical resynchronization. Circ Arrhythm Electrophysiol. 2019;12:e006934.

7. Dandamudi G, Vijayaraman P. How to perform permanent His Bundle pacing in routine clinical practice. Heart Rhythm. 2016;13:136266.

8. Verhaert D, Grimm RA, Puntawangkoon C, Wolski K, De S, Wilkoff BL, et al. Long-term reverse remodeling with cardiac resynchronization therapy. Circulation. 2010;122:985-92.
9. Peschar M, de Swart H, Michels KJ, Reneman RS, Prinzen FW. Left ventricular septal and apex pacing for optimal pump function in canine hearts. J Am Coll Cardiol. 2003;41:1218-26.

10. Chandra R, Zolty R, Palma E. A left hemiblock improves cardiac resynchronization therapy outcomes in patients with a right bundle branck block. Clin Cardiol. 2010;33:89-93.

11. Varma N. Left ventricular conduction delays and relation to QRS configuration in patients with left ventricular dysfunction. Am J Cardiol. 2009:103:1578-85.

12. Sing JP, Berger RD, Doshi RN, Lloyd m, Moore D, Stone J, et al.; ENHANCE CRT Study Group. Targeted left ventricular lead implantation in non-left bundle branch block patients: primary results of the ENHANCE CRT study. JACC Clin Electrophysiol. 2020;6(9):1171-81 .

13. Ploux $S$, Whinnett Z, Lumens J, Denis A, Zemmoura A, De Guillebon M, et al. Acute hemodynamic response to biventricular pacing in the heart failure patients with narrow, moderately, and severly prolonged QRS duration. Heart Rhythm. 2012;9:1247-50.

14. Sharma PS, Naperkowski A, Bauch TD, Chan JY, Arnold AD, Whinnett ZI, et al. Permanent His bundle pacing for cardiac resynchronization therapy in patients with heart failure and right bundle branch block. Circ Arrhythm Electrophysiol. 2018;11:e006613. 